\title{
PLURALIDAD DE RECLAMACIONES EN ACCIDENTES DE TRÁFICO TRANSFRONTERIZOS. COMENTARIO A LA SENTENCIA DE LA AUDIENCIA PROVINCIAL DE MADRID (SECCIÓN 20ª) DE 30 DE SEPTIEMBRE DE 2019
}

\author{
PLURALITY OF CLAIMS IN CROSS-BORDER TRAFFIC \\ ACCIDENTS.COMMENTARY TO THE JUDGMENT \\ OF COURT OF APPEAL OF MADRID (SECTION 20TH) \\ OF 30 SEPTEMBER OF 2019
}

\author{
Ángel Espiniella Menéndez* \\ Profesor titular de Derecho Internacional Privado (acreditado a catedrático) \\ Universidad de Oviedo \\ ORCID ID: 0000-0002-6241-6402
}

Recibido: 17.03 .2010 / Aceptado: 03.04.2020
DOI: https://doi.org/10.20318/cdt.2020.5646

Resumen: la Sentencia concluye con acierto la aplicación de la ley española a las acciones ejercitadas. Quizá hubiera sido posible una argumentación más exhaustiva para constatar que en el caso concurren dos tipos de acciones muy distintas. Por un lado, la acción directa del perjudicado, cuya regulación en el artículo 9 del Convenio de La Haya de 1971 apenas tiene protagonismo. Por otro, una acción subrogatoria de la aseguradora, excluida del Convenio y en la que reaparece una igualdad de armas procesales entre aseguradoras, y desaparece un principio de protección al perjudicado como parte procesalmente más débil. Además, la Sentencia es un buen ejemplo para exponer algunos de los problemas estructurales que plantea el Convenio de La Haya de 1971. La aplicación de la ley del lugar del accidente queda desplazada por la ley de la matrícula de los vehículos, siempre que todos los vehículos implicados estén matriculados en un mismo Estado. Y es precisamente este concepto de implicación el más dudoso en el Convenio.

Palabras clave: accidentes de tráfico transfronterizos, acción directa del perjudicado, acción subrogatoria de la aseguradora, Ley del lugar del accidente, Ley de la matrícula del vehículo.

Abstract: the Judgment correctly concludes the application of Spanish law to the claims brought by the claimants. Perhaps a more exhaustive argument would have been possible in order to verify that in the case there are two very different kinds of claims. On the one hand, the direct claim of the injured person, whose rules in Article 9 of the Hague Convention of 1971 has a little role. On the other hand, a subrogation action by the insurer, excluded from the Convention and in which an equality of procedural arms between insurers reappears, and a principle of protection for the injured party as a weaker party disappears. Furthermore, the Judgment is a good example to expose some of the structural problems posed

\footnotetext{
"Miembro del Grupo de Investigación Consolidado de Derecho Europeo de la Universidad de Oviedo(EURODER-UNIOVI-.IDI/2018/000187). El presente trabajo se adscribe al Proyecto de I+D DER2017-86017-R, "Obstáculos a la movilidad de personas en los nuevos escenarios de la UE”, concedido por el Ministerio de Economía, Industria y Competitividad, en los términos del artículo 37 de la Ley 14/2011, de 1 de junio, de la Ciencia, la Tecnología y la Innovación (BOE no 131, 2-VI-2011).
} 
by the Hague Convention of 1971. The application of the law of the place of the accident is displaced by the law of vehicle registration, provided that all vehicles involved are registered in the same State. Precisely this concept of implication is the most doubtful in the Convention.

Keywords: Cross-border traffic accidents.-Direct claim of the injured person.-Claim by subrogation of the insurer.-Law of the place of the accident-Law of registration of the vehicle.

Sumario: I. Planteamiento. II. Pluralidad de acciones en una litis internacional heterogénea: 1. La acción directa en un litigio mixto. 2. La acción subrogatoria en un litigio mixto. III. Pluralidad de vehículos matriculados en distintos Estados: 1. La implicación de vehículos matriculados en distintos Estados. 2. Noción procesal de implicación de vehículos. 3. Noción fáctica de implicación de vehículos. 4. ¿Una noción mixta? IV. Valoración.

\section{Planteamiento}

1. En la Sentencia de la Audiencia Provincial de Madrid (Sección $20^{\mathrm{a}}$ ) de 30 de septiembre de $2019^{1}$ se ejercitan dos tipos de acciones: la acción directa por parte del propietario del vehículo y sus pasajeros ocupantes, y la acción subrogatoria por parte de la compañía aseguradora. El vehículo siniestrado tiene matrícula en España, al igual que tiene domicilio en España la compañía aseguradora subrogante. Se reclama a las aseguradoras, también domiciliadas en España, de dos vehículos con matrícula española. En contraste, los elementos extranjeros son básicamente dos: el lugar donde se produce el accidente, Francia; y la implicación fáctica de dos vehículos de matrícula francesa, a cuyos responsables o aseguradoras no se les ha reclamado nada judicialmente, ni tampoco figuran como perjudicados.

2. La Sentencia se centra principalmente en cuestiones de ley aplicable. En este sentido, la Audiencia Provincial acierta al destacar la primacía del Convenio de La Haya de 4 de mayo de 1971, sobre ley aplicable a los accidentes de circulación, respecto del Reglamento (CE) n n 864/2007 ("Roma II"). Frente a la primacía genérica del Derecho de la UE, se recurre a la conocida compatibilidad con convenios anteriores al Reglamento en materias específicas de obligaciones extracontractuales, como es el caso que nos ocupa ${ }^{2}$. No queda muy claro en el caso si el recurrente invoca el Reglamento "Roma II" o no, pero sería un planteamiento equivocado.

Sea como fuere, convendría dar un paso más y que los tribunales tomen conciencia de las relaciones "ocultas" entre el Convenio de La Haya y el Reglamento "Roma II", y lo que se podría denominar cierta "complementariedad de facto" entre los distintos instrumentos. El Convenio tiene aplicación prioritaria al Reglamento "Roma II", pero este completa todos los aspectos sobre los que el Convenio no dispone nada. Entre esos aspectos no regulados por el Convenio y sí por el Reglamento, cabría apuntar la posible aplicación de las leyes de policía del foro en los términos del Reglamento "Roma II". Pero, quizá, el aspecto más destacado en el que puede haber un juego supletorio del Reglamento "Roma II" es el de la validez de la elección de ley por los interesados ${ }^{3}$. Para desarrollar esta idea de complementariedad, conviene referirse al Informe explicativo del Convenio ${ }^{4}$. Este señala que su silencio sobre la elección de ley no significa que la prohíba, sino que remite tal cuestión a las normas del Estado del foro ${ }^{5}$. Así pues, si el Estado del foro es un Estado miembro de la UE, como es el caso de España, admitirá la autonomía de la voluntad por efecto del Reglamento "Roma II".

\footnotetext{
${ }^{1}$ ECLI: ES:APM:2019:11054.

2 Artículo 28 del Reglamento.

3 Vid. A. Espiniella Menéndez, “Accidentes de circulación por carretera: del Convenio de La Haya de 4 de mayo de 1971 al Reglamento (CE) número 864/2007 (Roma II)”, AEDIPr, t. VII, 2007, pp. 505-532, pp. 512-515.

${ }^{4}$ Vid. el Informe explicativo al Convenio de La Haya de 1971 de E. W. Essén, Actas y Documentos de la XI Sesión de la Conferencia de La Haya, t. III, 1968 (también disponible en http://www.hcch.net), pp. 7-8.

${ }_{5}^{5}$ De la misma opinión, H. Hoyer, "Haager Straßenverkehrsübereinkommen und Rechtswahl der Parteien", ZfRV., vol. 32 , 1991, pp. 341-348, esp. p. 347.
} 
En cualquier caso, tómese esta relación de complementariedad como una consideración previa y general, pues en el supuesto no consta ningún atisbo de elección de ley. Al contrario, consta una discrepancia sobre dicha ley aplicable.

3. Confirmada la aplicación del Convenio de La Haya, la Audiencia asume que la prescripción de la acción, aspecto verdaderamente debatido en la resolución, es una cuestión de fondo que debe regirse por la ley aplicable a la responsabilidad por daños. Así se establece en el artículo 8 del Convenio, que se refiere a la ley de fondo para regir "las prescripciones y caducidades por expiración de un plazo, con inclusión del comienzo, la interrupción y la suspensión de los plazos". Añade la Sentencia una crítica a lo que denomina el "espigueo normativo", según el cual el demandante busca "aplicar de forma indistinta la legislación española o la francesa según sea más o menos beneficiosa para la parte demandante". Debe coincidirse en la improcedencia de esta práctica. La ley rectora de fondo será una sola y no cabrá un depeçage de esta o fraccionamiento de la ley aplicable en función de las cuestiones afectadas. No hay base legal alguna para permitir este fraccionamiento en el Convenio de La Haya. Es más, la hay para lo contrario, para afirmar la unidad de la ley aplicable para todas las cuestiones que el Convenio considera el "alcance de la ley aplicable".

4. Expuesta la litis, dos elementos dan a la Sentencia un valor especial: la pluralidad de acciones ejercitadas y la pluralidad de vehículos implicados.

\section{Pluralidad de acciones en una litis internacional heterogénea}

\section{La acción directa en un litigio mixto}

5. En un caso como el presente, la competencia de los tribunales españoles es clara. De hecho, no es motivo alegado en el recurso. Merece, no obstante, un mínimo comentario por el ejercicio de dos tipos de acciones: la directa y la subrogatoria. La acción directa es ejercitada por las víctimas frente a las aseguradoras, que tienen, a todos los efectos, domicilio en la UE. Precisamente por esta razón resulta de aplicación el Reglamento (UE) n 1215/2012 ("Bruselas I.bis") y, en particular, su sección sobre contratos de seguros. De acuerdo con estas normas, los tribunales españoles son competentes por el domicilio del demandado.

6. Como matices, merecen unas mínimas reflexiones el solapamiento de foros, la competencia interna y los problemas de un litisconsorcio pasivo. Comenzando por el solapamiento de foros, debe repararse en que no solo está en España el domicilio de los demandados, sino que también parece que está el domicilio de los demandantes, lo cual de por sí es otra regla de competencia ${ }^{7}$. Ante tal solapamiento, debe hacerse primar la regla de competencia basada en el domicilio del demandado. No solo porque es la norma general, sino, porque, literalmente, el artículo 11 se refiere al domicilio del demandante cuando permite presentar la demanda "en otro Estado miembro", es decir, en un Estado miembro distinto al del domicilio de los demandados.

La duda sobre si la base legal de competencia es el domicilio del demandado o el domicilio de los demandantes es importante en la práctica. La primera solo establece la competencia judicial internacional de los tribunales españoles, pero no la competencia interna, que deberá determinarse por la Ley de Enjuiciamiento Civil. La segunda establece tanto la competencia internacional como la competencia interna.

\footnotetext{
${ }^{6}$ Como cuestión absolutamente menor, quizá convendría destacar que este espigueo no es tanto aplicar de "forma indistinta" una ley u otra, como señala la Sentencia. En efecto, la práctica de aplicar de "forma indistinta" varias leyes se ha utilizado en alguna ocasión para corroborar que la ley del foro, la ley española, llega al mismo resultado que la ley de fondo, la cual no ha sido suficientemente probada. Al contrario, en el caso analizado y que la Sentencia bautiza como un "espigueo" la aplicación de una u otra ley es cualitativamente distinta, porque los resultados a los efectos de entender la existencia o no de prescripción varían notablemente.

${ }^{7}$ Artículos 11 y 13 del Reglamento "Bruselas I.bis" en una cuestión que, en su día, generó polémica sobre si el perjudicado podía demandar en su propio domicilio.
} 
7. Enlaza lo expuesto con una segunda cuestión de interés, la competencia para un litisconsorcio pasivo, pues no se olvide que se demanda a dos aseguradoras de dos vehículos distintos. De nuevo aquí debe distinguirse entre competencia internacional e interna. En el Reglamento "Bruselas I.bis", no se contempla el foro del litisconsorcio pasivo en materia de seguros, a diferencia de lo que ocurre en otras relaciones contractuales asimétricas, básicamente, la de trabajadores ${ }^{8}$. Ello significa que el demandante no puede valerse del tribunal del domicilio de cualquiera de los codemandados, aún cuando es patente la relación entre las reclamaciones contra las aseguradoras, al tratarse de un mismo accidente donde se vieron envueltos al menos tres vehículos.

Pero la solución es distinta en el ámbito de la competencia interna. Afirmada la competencia internacional de los tribunales españoles para los dos demandados, así como la remisión a la Ley de Enjuiciamiento Civil para concretar la competencia territorial, no parece que haya ningún problema en aplicar los fueros de la ley interna sobre litisconsorcios?. Se respeta la normativa del Reglamento "Bruselas I.bis", pues no se crea un foro de competencia internacional. Solo se aprovecha la coincidencia de que las dos aseguradoras demandadas, individualmente consideradas, pueden ser requeridas ante los tribunales españoles.

8. En cualquiera de los casos, y entrando ya en cuestiones de ley aplicable, en la argumentación de la Sentencia se echa en falta una alusión al régimen de ley aplicable de la acción directa contra la aseguradora, previsto en el artículo 9 del Convenio de La Haya. Este dispone que las "personas perjudicadas tendrán derecho a actuar directamente contra el asegurador del responsable" cuando lo disponga la ley de la matrícula aplicable al caso. Si esta ley "no reconociera este derecho", también podrá ser ejercido si está reconocido por la ley del lugar del accidente. A falta de previsión por este segundo ordenamiento, el derecho de acción directa asistirá al perjudicado si lo prevé la ley del contrato del seguro.

La dicción literal no es menor en el caso, porque, precisamente, parece que el demandante tiene derecho a la acción directa conforme a la ley española por no haber prescrito, mientras que, según el demandado, no tiene ese derecho conforme a la ley francesa por haber prescrito. La ley española sería aplicable como ley de la matrícula (conexión 1) y como ley del contrato de seguro (conexión 3); la francesa, como ley del accidente (conexión 2) ${ }^{10}$.

9. En este contexto, y de una forma no muy clara, parece que los demandados invocan la ley francesa (conexión 2) para entender que la acción está prescrita. Este proceder no es sostenible por dos razones. La primera, que la ley española era aplicable a título de ley de la matrícula (conexión 1), sin perjuicio de que no sea una cuestión sencilla como se verá más adelante. Baste ahora señalar que todos los vehículos afectados por el proceso tienen su matrícula en España, de forma que la ley de la matrícula se presenta como una excepción a la aplicación de la ley del lugar del accidente (conexión 2).

Pero, hay, a mayor abundamiento, una segunda razón para entender improcedente la invocación de la ley francesa. El afán de los demandados de demostrar que no debe aplicarse la conexión 1, la ley de la matrícula, sino la conexión 2, la ley del accidente, no debe ocultar que también podría jugar la conexión 3, la ley del contrato. El paso de una conexión a otra debe hacerse en concreto en función de las circunstancias del caso. No basta con comprobar que la acción está genéricamente prevista en un ordenamiento, por ejemplo, en el ordenamiento francés ${ }^{11}$, sino de demostrar que es viable en el caso concreto, por ejem-

\footnotetext{
${ }^{8}$ Artículo 20 que remite al artículo 8 cuando el trabajador pretenda demandar a dos o más empresarios.

${ }^{9}$ Artículo 53 de la Ley Enjuiciamiento Civil.

${ }^{10}$ Sobre esta cuestión, Raúl LAfUENTE SÁnchez, "Plazos de prescripción y normas internacionalmente imperativas en el ámbito de la ley aplicable a las acciones derivadas de accidentes de tráfico transfronterizos", La Ley Unión Europea, $\mathrm{n}^{\circ}$ 69, abril 2019, pp. 1-19, si bien en referencia al Reglamento "Roma II" y a la posible consideración de estas cuestiones como leyes de policía del foro.

${ }^{11}$ En esta valoración general, se trata de constatar que la acción directa está prevista en un ordenamiento, al margen de que no sea viable en el caso concreto. Esta interpretación se basaría en que el artículo 9 sobre acción directa regula aspectos procesales de esta acción, pero no cuestiones sustantivas de responsabilidad y, recuérdese, que la prescripción y la caducidad se consideran cuestiones de fondo.
} 
plo, por no haber prescrito o caducado ${ }^{12}$. En este contexto, la dicción literal del Convenio relativa a "tener derecho" podría entenderse como una garantía individual, un derecho subjetivo para el demandante en función del caso concreto ${ }^{13}$. Máxime cuando luego se refiere a los casos en los que "no se reconociera este derecho". De nada parece servir un reconocimiento genérico de la acción directa en la ley francesa, si luego el perjudicado no tiene en el caso concreto ese derecho ${ }^{14}$. Así pues, si la acción está prescrita en la ley 1, cabe invocar la ley 2; pero, si la acción está prescrita en la ley 2, cabe invocar la ley 3.

Esto significa que, dispusiera lo que dispusiera la ley francesa (conexión 2) y se concluya lo que se concluya respecto de si es aplicable la ley de la matrícula (conexión 1), la ley española reaparecería como ley rectora del contrato de seguro. Si esta ley da derecho a la acción directa sin que haya prescrito, esta parece incuestionable. No cabe duda de que el contrato de seguro de los vehículos responsables, con matrícula y estacionamiento habitual en España, se va a regir por la ley española, en tanto que trate de cubrir la obligación de aseguramiento por circulación de vehículos en España ${ }^{15}$.

\section{La acción subrogatoria en un litigio mixto}

10. Las entidades prestadoras de cobertura pueden dirigirse contra los responsables del siniestro y contra las aseguradoras que eventualmente cubran sus actividades ${ }^{16}$. Esto es precisamente lo que ocurre en el caso.

En el ámbito procesal, el ejercicio de una acción por subrogación no plantea mayores problemas si la demanda se presenta ante los tribunales del domicilio del demandado ${ }^{17}$. Aparte de este foro general, no se pueden invocar los foros relativos a seguros. Se considera que los foros en materia de seguro están configurados para una parte intuitu personae con una posición jurídica y económica más débil, que no se cumple cuando actúa la aseguradora por subrogación ${ }^{18}$. En cambio, cuando, como ocurre en el caso, la aseguradora se ha subrogado en una obligación no contractual, cabrá utilizar los foros propios a esta y, en particular, el lugar del accidente. Otros lugares donde se observan pérdidas patrimoniales de la aseguradora no pueden considerarse foros atributivos de competencia. Así, el lugar donde se produjo el pago de la indemnización no muestran una conexión relevante.

11. Por lo que respecta a la ley aplicable a las acciones subrogatorias, estas, en principio, quedan excluidas del Convenio de La Haya de $1971^{19}$. Si la aseguradora se subroga en una relación no contractual del asegurado, se aplicará el Reglamento "Roma II"20. La ley rectora de la obligación de reparación

12 Vid. P. JimÉnez Blanco, "El régimen de las acciones directas en el Reglamento de Roma II”, AEDIPr., t. VII, 2007, pp. 287-313, p. 293. En la jurisprudencia comparada, vid. la Sentencia del Juez de Distrito de Lucerna de 9 de junio de 1999 , SwissLex, núm. 1501, 1999.

${ }_{13}$ Vid., en este sentido, la Sentencia de la Corte de Casación francesa de 2 de octubre de 1984, Bulletin, núm. 244, 1984-I.

${ }^{14} \mathrm{Vid}$. A. Espiniella MenÉndez, "Cobertura de daños causados en accidentes de circulación por carretera de ámbito internacional”, AEDIPr, t. IV, 2004, pp. 1078-1083, esp. p. 1083; P. JimÉNEZ BLANCO, loc. cit., p. 289, nota 19.

${ }^{15}$ Artículo 7.4 del Reglamento "Roma I". La clara aplicación de la ley española a los plazos de prescripción hace innecesario recurrir a un tercer argumento, que podría tener cierta importancia en otros casos. Este no sería otro que la posibilidad o no de considerar los plazos de prescripción una ley de policía del foro por su importancia esencial, de forma que fueran aplicables dispusiera lo que dispusiera la ley de fondo. En referencia al Reglamento "Roma II", vid. STJUE de 31 de enero de 2019, Agostinho da Silva Martins, asunto C149/18, ECLI:EU:C:2019:84, y, al respecto, R. LAFUENTE SÁNChez, loc. cit.

${ }^{16}$ En la práctica, la SAP de Madrid de 10 de abril de 2000, AEDIPr., t. II, 2002, pp. 1035-1036, aunque anterior a la normativa vigente.

${ }^{17}$ Artículos 4 del Reglamento "Bruselas I.bis" y del Convenio de Lugano.

18 Vid., STJCE de 17 de septiembre de 2009, asunto C-347/08, Vorarlberger, ECLI:EU:C:2009:561. En otros ámbitos, la Sentencia de 15 de febrero de 2004, asunto C-265/02, Frahuil c. Assitalia, ECLI:EU:C:2004:77.

19 vid. P. Bourel, "Responsabilité civile", Rép. Int. Dalloz, 1998, §§ 1-165, § 140; G. Beitzke, "Die 11. Haager Konferenz und das Kollisionsrecht der Strassenverkehrsunfälle", RabelsZ., vol. 33, 1969, pp. 204-234, esp. pp. 217-218; A. Junker, "Das Internationale Privatrecht der Strassenverkehrsunfälle nach der Rom II-Verordnung”, J.Z., vol. 63, 2008, pp. 169-178, p. 177; C. S. Armstrong, "The Hague Convention on the Law Applicable to Traffic Accidents: Search for Uniformity Amidst Doctrinal Diversity", Col. J. Transnat'l. L., vol. 11, 1972, pp. 74-103, p. 78.

20 vid. P. Blanco-Morales Limones, El seguro español en el Derecho internacional privado, Madrid, Caser, 1989, pp. 421-422. 
del daño determina el objeto de la subrogación, es decir, qué, cuánto y cómo se puede exigir al responsable ${ }^{21}$. Por su parte, la ley rectora del contrato de seguro determina si la aseguradora se puede subrogar y con qué alcance ${ }^{22}$.

\section{Pluralidad de vehículos matriculados en distintos Estados}

\section{La implicación de vehículos matriculados en distintos Estados}

12. La aplicación del citado Convenio de La Haya de 1971 puede entenderse correcta. Concurren los requisitos para aplicar la ley española, como ley de la matrícula de los vehículos afectados por el proceso. Todos los vehículos afectados por el proceso están matriculados en España; todos, además, parecen mostrar un vínculo real y efectivo entre la matrícula formal y el Estado de matriculación. Por lo menos no existen indicios para entender que el Estado de la matrícula no se corresponde con el de residencia habitual de, al menos, el propietario, el poseedor o el conductor.

De todo ello resulta que la ley española, como ley de la matrícula, tiene preferencia, como excepción, respecto de la regla general, la ley francesa como ley del lugar del accidente ${ }^{23}$. Se trata de una argumentación correcta de la Sentencia a la que poco o nada hay que reprochar.

No obstante, hay un aspecto que debería llamar la atención en el caso: la eventual presencia de vehículos de matrícula francesa en el siniestro. En efecto, de acuerdo con el artículo 4.b) del Convenio, si "estuvieran implicados varios vehículos", solo se aplica la ley de la matrícula si "todos los vehículos estuvieren matriculados en el mismo Estado". Aplicado al caso, la ley española como ley de la matrícula dejaría de aplicarse en favor de la ley francesa del lugar del accidente, y no todos tuvieran el mismo Estado de matriculación. ¿Por qué, entonces, en la presente Sentencia no se tiene en cuenta la presencia de varios vehículos de matrícula francesa? En las próximas líneas se tratará de contestar a esta pregunta, sin ánimo de criticar a una Sentencia que resuelve el caso con suficiente solvencia.

\section{Noción procesal de implicación de vehículos}

13. La respuesta a la implicación de varios vehículos con matrícula de distinto Estado no es sencilla y no debe imputarse a la Sentencia un problema que es estructural al Convenio, como es la falta de definición de qué se entiende por "vehículos implicados".

Podría entenderse, en una primera lectura, que se trata de un concepto de "implicación procesal", es decir, en el caso: los vehículos franceses estarían implicados si los responsables o sus aseguradoras tienen alguna posición procesal en el litigio. Estaríamos ante supuestos en los que los responsables o aseguradoras de los vehículos franceses aparecen como demandados en el litigio. También debería entenderse que existe una implicación procesal si estos responsables no son inicialmente demandados, pero sí son llamados al proceso a modo de intervención de terceros por su responsabilidad. Las ventajas de este modelo pasan básicamente por la fácil interpretación del concepto de implicación, pues bastará la constatación de las partes en el proceso para su correcta aplicación. Precisamente esta interpretación es la que asume la Sentencia y nada debe reprocharse. Nadie ha planteado incidencia alguna de los vehículos de matrícula francesa, por lo que es comprensible recurrir a la ley española de matrícula, por ser la de todos los vehículos con intereses en el proceso.

${ }^{21}$ Vid. A. Malatesta, "La legge applicabile agli incidente stradali nella proposta di Regolamento (CE) Roma II”, Riv. dir. int. priv. proc., vol. XLII, 2006, pp. 47-66, p. 62; G. CAMPEIS y A. DE PAULI, Il Diritto internazionale della circolazione stradale, Milán, Giuffré Ed., 1997, p. 399.

22 vid. L. Schuermans y P. Lavrysen-van Eupen, "Les accidents de la circulation en droit international privé belge”, Rev. $d r$. int. et dr. comp. , t. LI, 1974, pp. 7-49, esp. p. 28.

${ }^{23}$ Artículo 3 del Convenio. 


\section{Noción fáctica de implicación de vehículos}

14. La otra noción de implicación sería el de "implicación fáctica" de vehículos con matrícula de otro Estado. Ello significa que la intervención en el siniestro de estos vehículos ya desactivaría la aplicación de la ley de la matrícula. Su ventaja sería posiblemente una solución más propia de Derecho aplicable y sustantivo, sin depender de las estrategias procesales de las partes. Máxime cuando estas estrategias pueden ser variadas en función del número de demandantes, el número de demandados, el tipo de acciones conjunta o directa contra la aseguradora, y del número de Estados en los que se podría interponer la demanda. El principal inconveniente de esta "implicación fáctica" está relacionado con la falta de definición de qué se entiende por implicación y cuál puede ser su alcance. ¿Es la misma implicación la de un vehículo que se salta una señal de stop que la de un vehículo que simplemente evita la colisión con una maniobra y sufre un pequeño desperfecto en el vehículo? Se trata de una cuestión sobre la que el Convenio no se pronuncia.

En cualquier caso, la implicación fáctica de varios vehículos parece referirse tanto a los vehículos responsables como a los perjudicados. No se trata de exigir el mismo Estado de matrícula solo a los vehículos responsables, sino, también, a otros vehículos perjudicados. Y todo ello dejando al margen cuál sea la intensidad del daño sufrido o de la implicación en la responsabilidad. Llevado al caso, se desactivaría la ley española de la matrícula si los vehículos franceses han sufrido daños, aunque sean mínimos, o son potenciales responsables, aunque sean también en un grado leve.

\section{4. ¿Una noción mixta?}

15. Cabría, por último, una definición mixta de "implicación" que asuma postulados sustantivos y procesales. Se partiría de la implicación fáctica antes descrita, un mínimo daño o una mínima responsabilidad, pero esta implicación fáctica se constataría con la estrategia procesal presente. Si los demandantes piden el $100 \%$ de la responsabilidad a los responsables de los vehículos españoles, y estos no llaman al proceso a los responsables de los vehículos franceses, cabe presumir que no hay implicación fáctica. Podría entenderse que hay unos hechos admitidos, la exención de responsabilidad de los vehículos franceses. De nuevo, la conclusión de la Sentencia objeto de comentario podría encajarse en esta noción.

De todas formas esta noción mixta no solucionaría el problema de varios vehículos perjudicados de distinta matrícula, aún cuando haya consenso sobre qué vehículo puede ser el responsable.

16. Las dificultades del concepto de "implicación" se agravan todavía más si se genera en un escenario procesal de procesos pendientes en distintos Estados. Se trata de una hipótesis de estudio interesante, aunque no consta que haya sucedido en el caso. Pero, por utilizar este caso como ejemplo, no sería descartable que los eventuales perjudicados de los vehículos franceses presentaran una demanda en Francia contra los aquí demandados o, incluso, contra los ahora demandantes. En puridad, no habría identidad de partes entre los procesos, pues los perjudicados de los vehículos franceses no se encuentran personados en España. Se trataría, pues, de un caso de conexidad más que de litispendencia. Pero ello no obstaría la conveniencia de acumular ambos procesos, ya que los riesgos de soluciones incompatibles son notorios. Incompatibilidad jurídica, porque, a la constatación de que en España se está aplicando la ley española por la "implicación" procesal solo de vehículos españoles, se uniría la más que probable aplicación en Francia de la ley francesa, al estar implicados vehículos españoles y franceses. Pero, además de jurídica, cabría referirse a una incompatibilidad fáctica, porque la valoración de unos mismos hechos por dos tribunales podría ser contradictoria. En un proceso cabría entender responsable a uno de los vehículos mientras que, en el segundo proceso, podría considerarse responsable a otro de los vehículos.

A mi juicio, ante esta situación se originan dos consecuencias. Una procesal, de forma que se proceda a la acumulación ante el tribunal que conozca en primer lugar. Ese primer tribunal sería competente, bien por ser el del lugar del accidente, bien por ser el del domicilio de los demandados, si se asume la hipótesis de que los demandados seguirían siendo los responsables de los vehículos españoles. 
En todo caso, no habría posibilidad de acumulación por falta de competencia en otros casos en los que los perjudicados demanden en su propio domicilio, distinto al de otros perjudicados.

La segunda consecuencia sería en la ley aplicable, y pasaría por entender que, si en Francia se abre un proceso en el que se personan los propietarios de los vehículos franceses, se constata la "implicación" de vehículos de matrículas de diferentes Estados. Por tanto, el juez español, advertida esta situación, debería resolver conforme a la ley francesa, como ley del lugar del accidente, al constatar vehículos implicados de distinta matrícula. Debería obviar la ley española de matriculación de alguno de los vehículos implicados.

\section{Valoración}

17. La Sentencia concluye con acierto la aplicación de la ley española a las acciones ejercitadas. En su debe, quizá una argumentación más exhaustiva para constatar que en el caso concurren dos tipos de acciones muy distintas. Por un lado, la acción directa del perjudicado, cuya regulación en el artículo 9 del Convenio de La Haya de 1971 apenas tiene protagonismo. Por otro, una acción subrogatoria de la aseguradora, excluida del Convenio y en la que reaparece una igualdad de armas procesales entre aseguradoras, y desaparece un principio de protección al perjudicado como parte procesalmente más débil.

Además, la Sentencia es un buen ejemplo para exponer algunos de los problemas que plantea el Convenio de La Haya de 1971. La aplicación de la ley del lugar del accidente queda desplazada por la ley de la matrícula de los vehículos, siempre que todos los vehículos implicados estén matriculados en un mismo Estado. Y es precisamente este concepto de implicación el más dudoso en el Convenio. Falta una definición fáctica de implicación y una definición procesal, en función de las partes personadas en un proceso, tampoco omite el riesgo de que se abran procesos en otros Estados.

Todo ello es una muestra más de que el Convenio de La Haya de 1971 no ha soportado bien el paso del tiempo y que va siendo hora de valorar su denuncia por parte de los Estados miembros de la UE que lo aplican. Ello nos situaría en un nuevo escenario de aplicación del Reglamento "Roma II" sobre ley aplicable a las obligaciones no contractuales. Aunque también es cierto que este Reglamento tampoco ha prestado especial atención a la pluralidad de implicados en un accidente y, en particular, si la búsqueda de una ley más estrechamente vinculada debe hacerse en términos individuales de cada perjudicado o en términos globales para todos los responsables y perjudicados implicados. 